\title{
SUMMARY OF SCAN SITE 7
}

\author{
G. W. Moore, U. S. Geological Survey, La Jolla, California \\ and \\ G. F. Sharman, Scripps Institution of Oceanography, La Jolla, California
}

\section{OBJECTIVE OF DRILL HOLE}

The revised location for Site 7 is latitude $33^{\circ} 05^{\prime} \mathrm{N}$, longitude $140^{\circ} 00^{\prime} \mathrm{W}$, and the water depth is $5020 \mathrm{me}-$ ters. This site is one of a series along the 140th meridian that will investigate latitudinal variations in lithologic and biologic deep-sea stratigraphy.

\section{SURVEY METHODS}

The survey of this site was made from the Argo between March 24-26, 1969. Positioning was by a satellite navigation system in which the refraction-correction function had failed. Fix precision is estimated at about 4 kilometers, and the fix frequency was less than 1 every two hours. Two star positions were also plotted during the course of the survey. Magnetic-intensity traverses and acoustic-reflection profiles at $12,3.5$ and $0.1 \mathrm{kHz}$ were run on a grid 75 kilometers square, with tracks about 20 kilometers apart. On the accompanying subbottom profiles, a 10 -second sweep was used, and the spacing between hour marks is about 20 kilometers. A piston core was taken near the drilling site.

\section{NATURE OF SITE}

The sediment in this area has a rather uniform thickness of about 50 meters. No microfossils were found in the 10-meter core; and, its base, which contains micronodules, is grayish-brown and similar to that at Site 6.

\section{MICROPALEONTOLOGY}

\author{
David Bukry \\ U. S. Geological Survey, La Jolla
}

\section{General Comments}

Samples taken at 1.5-meter intervals from the piston cores, recovered during the preliminary surveys of the proposed Deep Sea Drilling Project sites in the northeast Pacific, have been examined for calcareous nannofossils. The identified assemblages of nannofossils indicate that Pliocene sediment containing abundant discoasters is present in the upper 10 meters at only one place, Site 6. Elsewhere, only Pleistocene assemblages are present in the upper 10 meters. The abundant, widely distributed Holocene nannofossil, Emiliania huxleyi (Lohmann) is not represented in any of the samples examined.

Diatoms are common only in surface samples ( 0 to 1 centimeter) at Sites 1,2 and 4. Foraminifera are sparsely present in several samples from Sites 1, 2, 4, 5 and 6.

\section{SCAN-7-P}

Core length: 9.5 meters. All samples are devoid of calcareous and siliceous microfossils. 


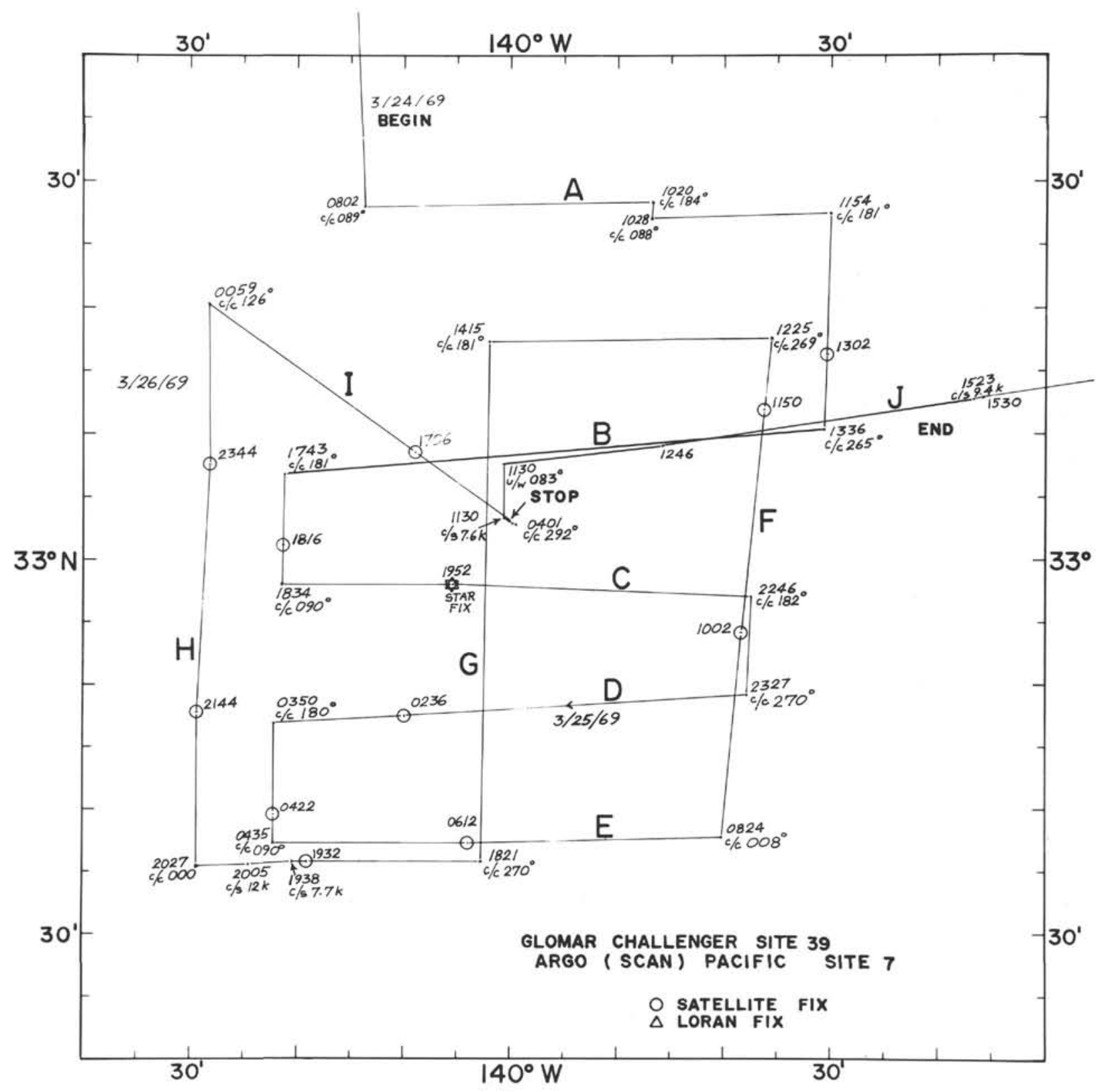




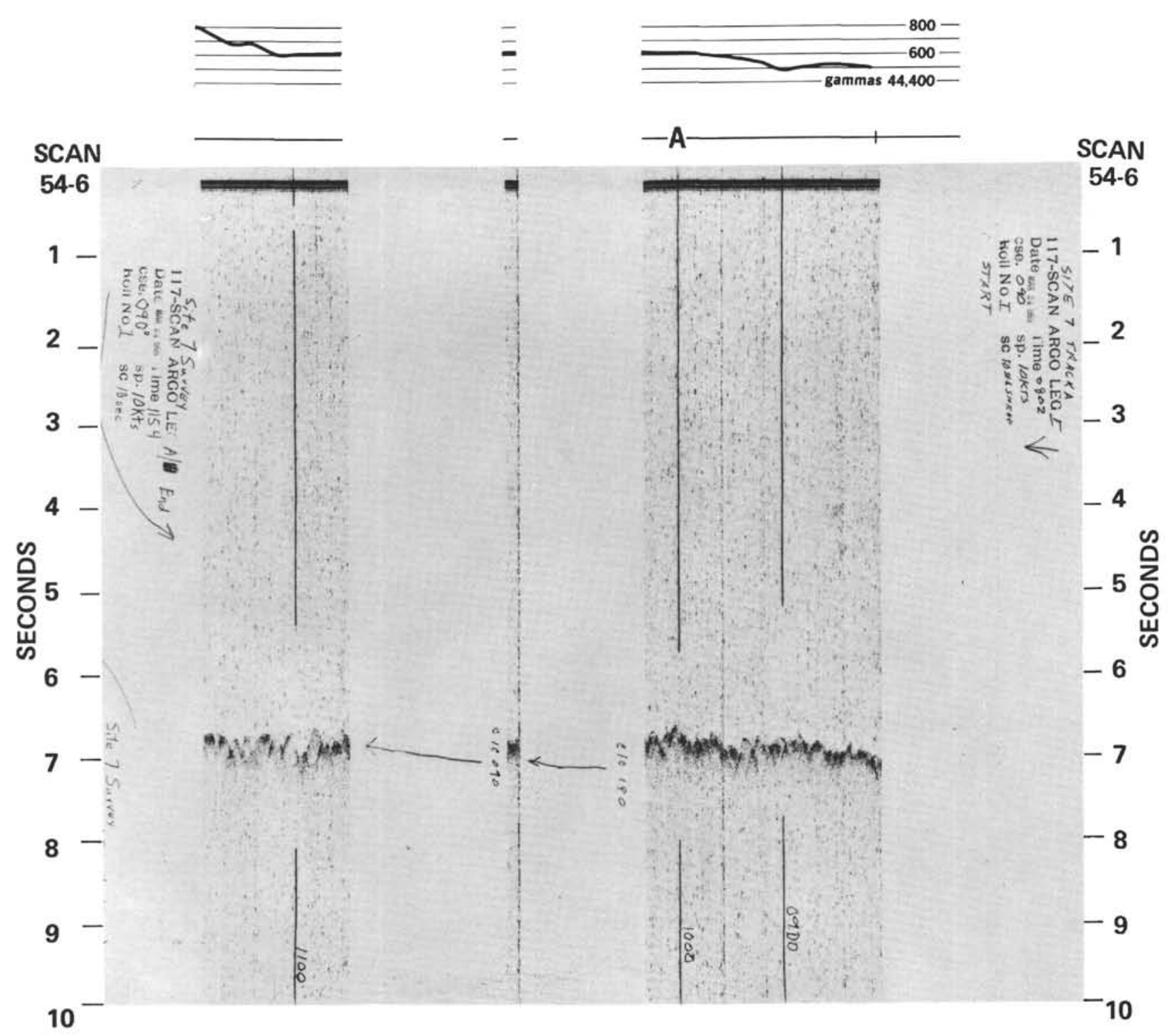

SCAN Survey, Site 7, Track A. 


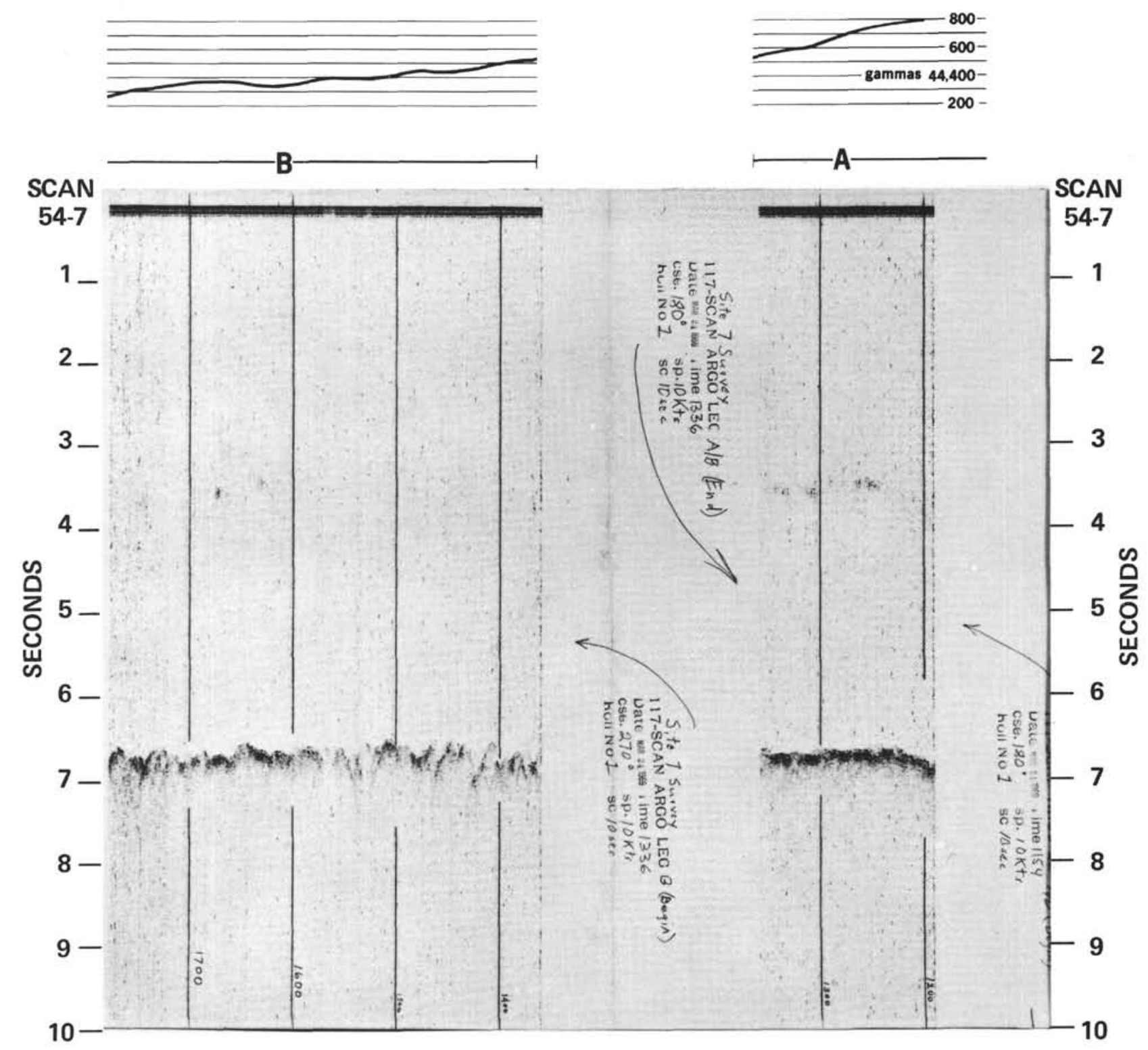

SCAN Survey, Site 7, Tracks $A$ and $B$. 


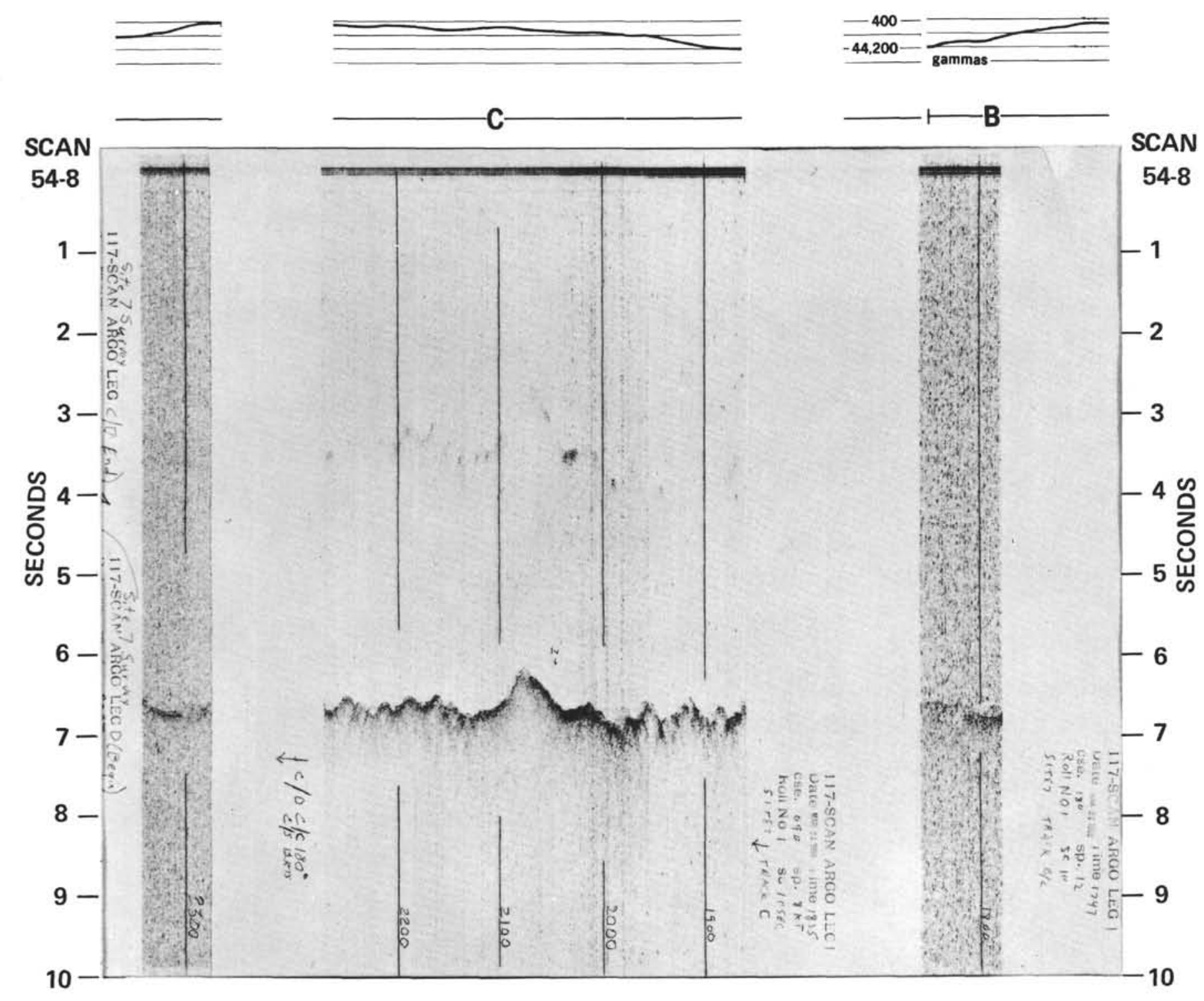

SCAN Survey, Site 7, Tracks $B$ and $C$. 


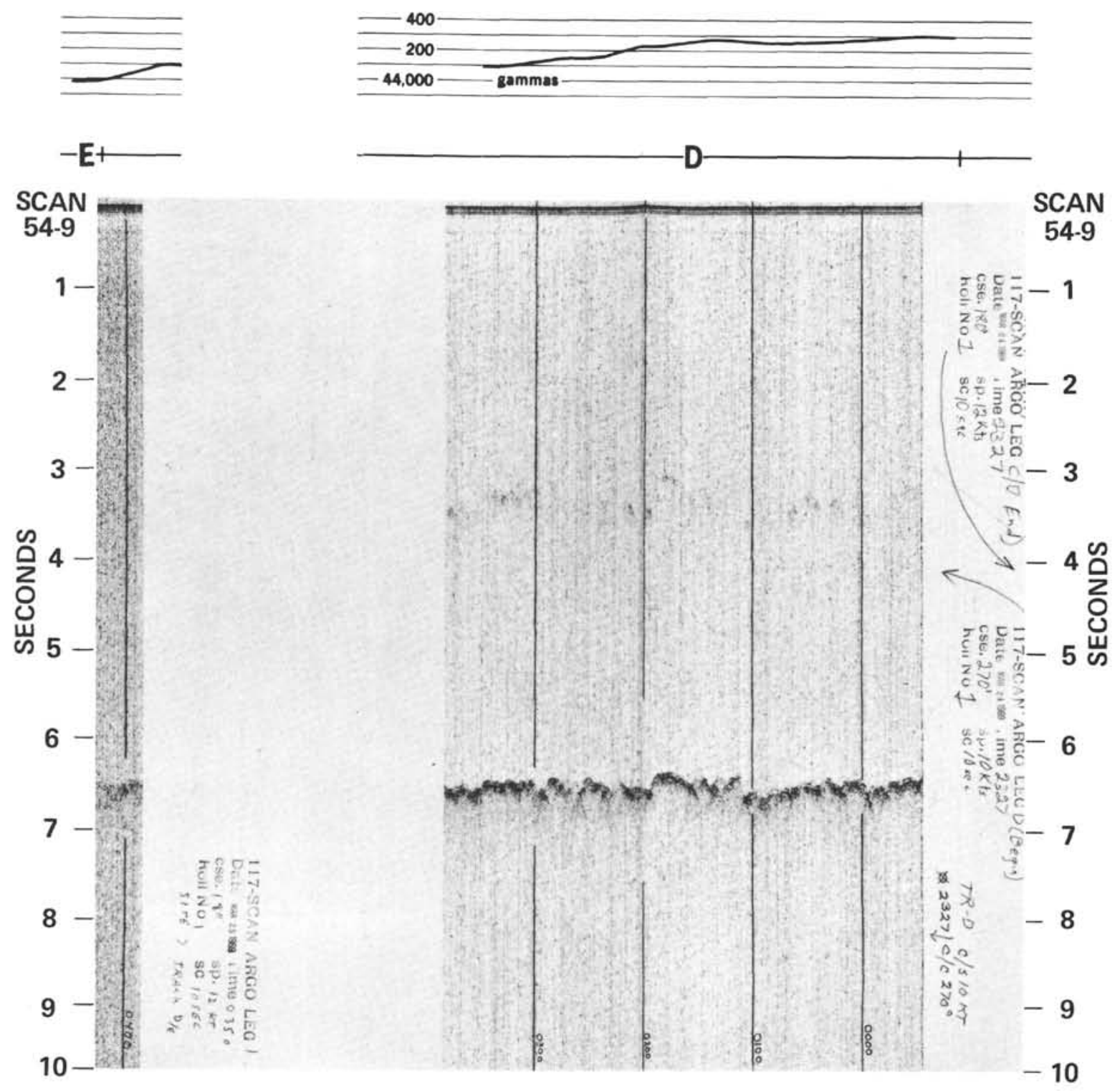

SCAN Survey, Site 7, Tracks D and E. 


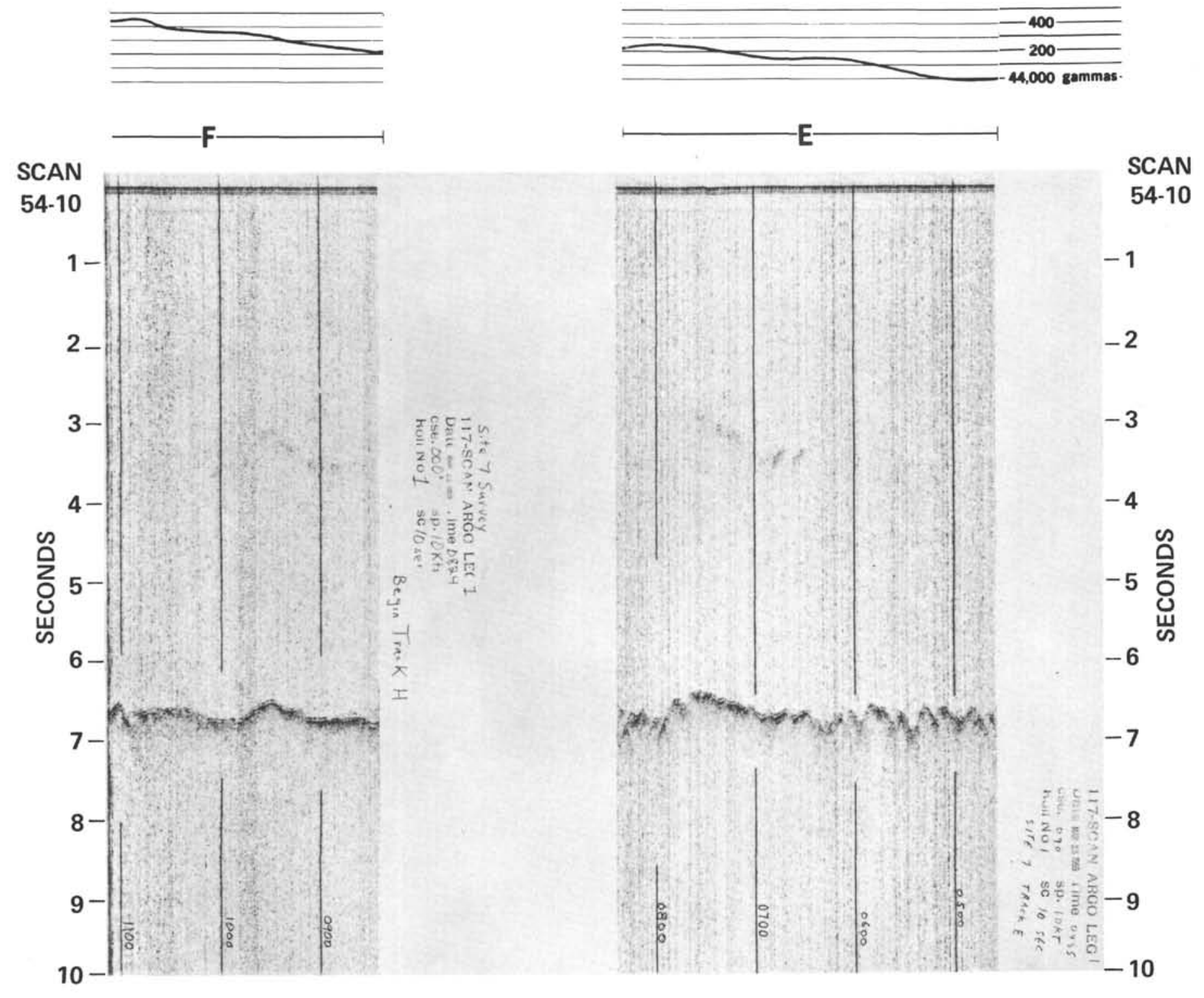

SCAN Survey, Site 7, Tracks $E$ and F. 

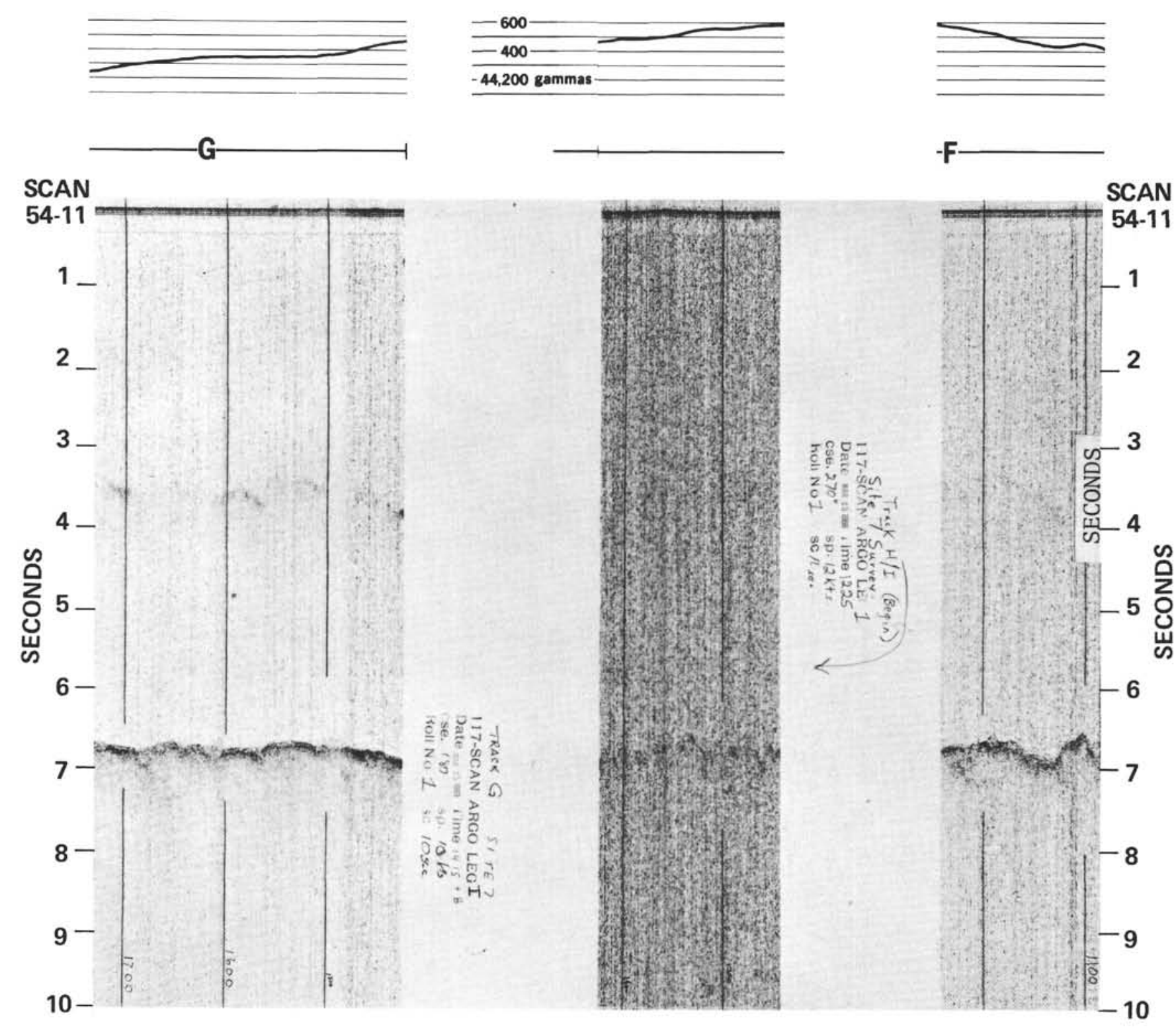

SCAN Survey, Site 7, Tracks $F$ and $G$. 

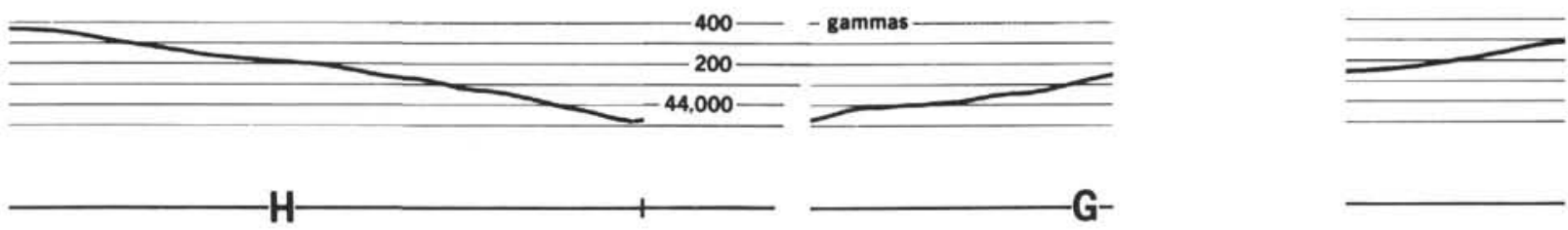

SCAN

54-12 =
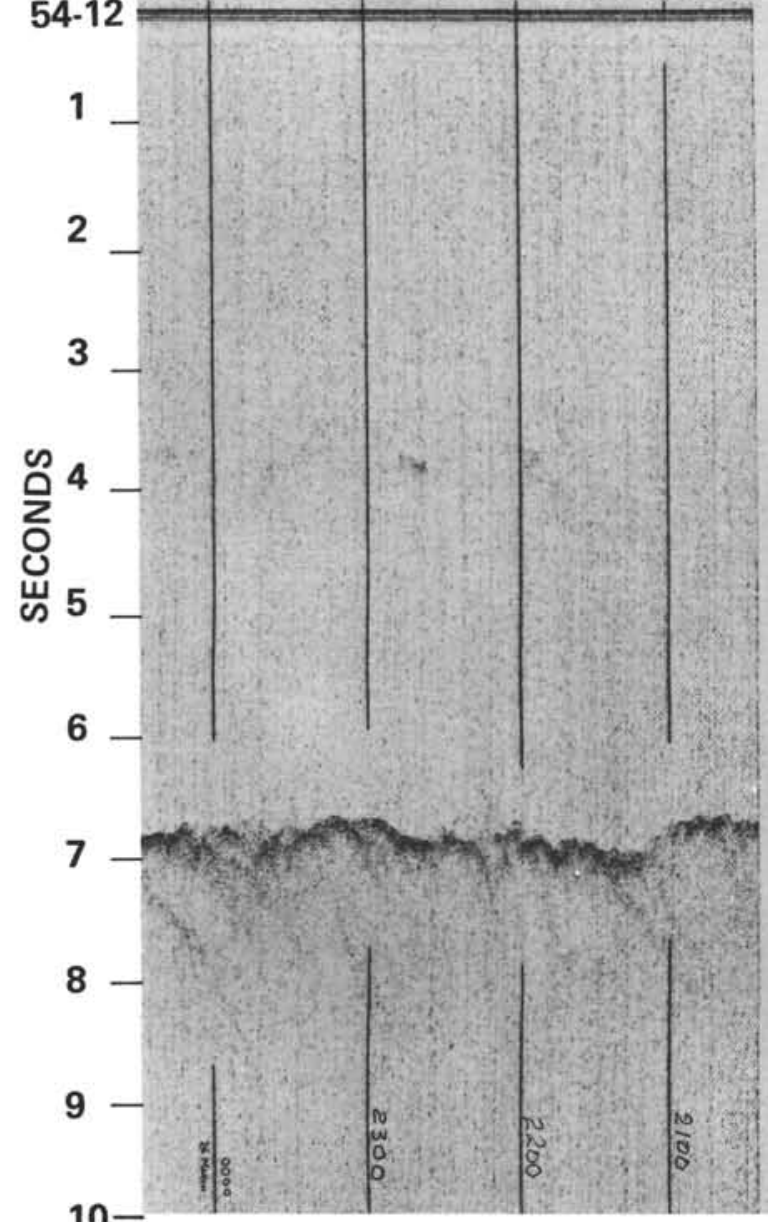

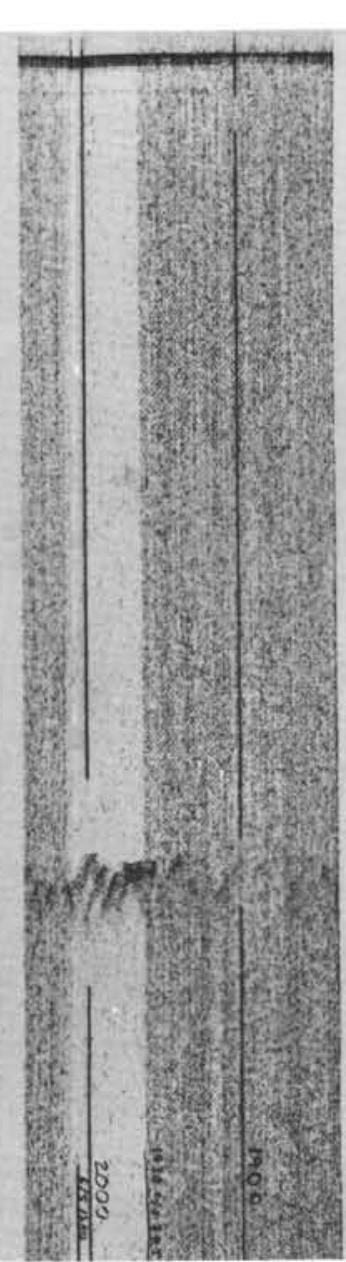

SCAN

54-12

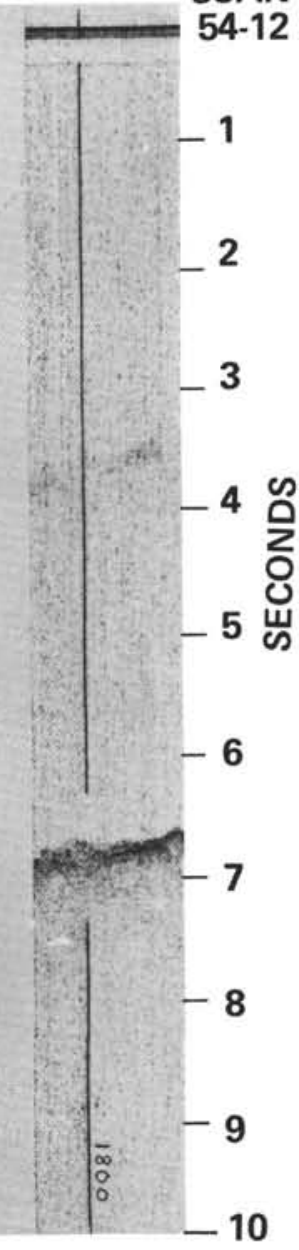

SCAN Survey, Site 7, Tracks $G$ and $H$. 


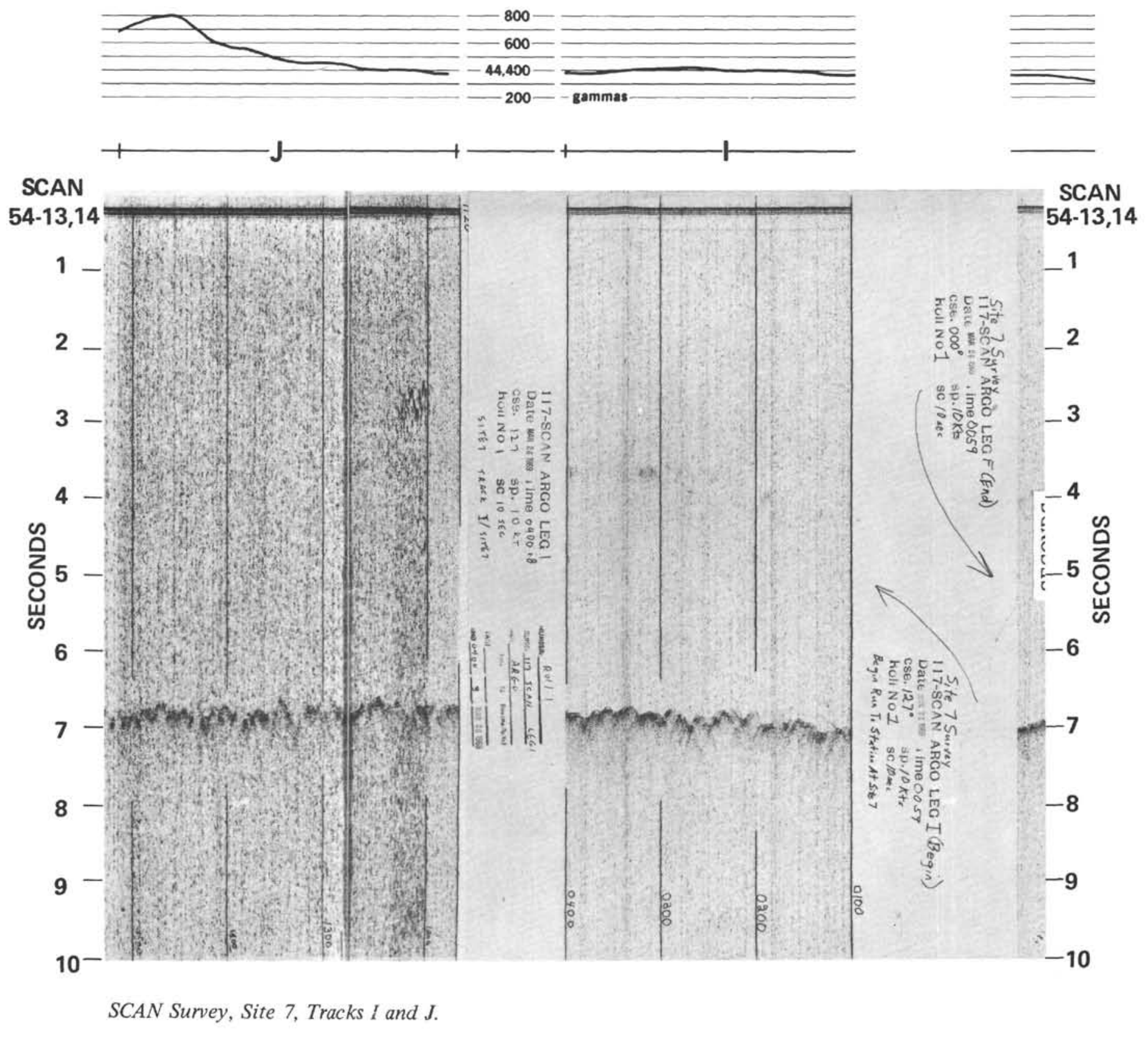




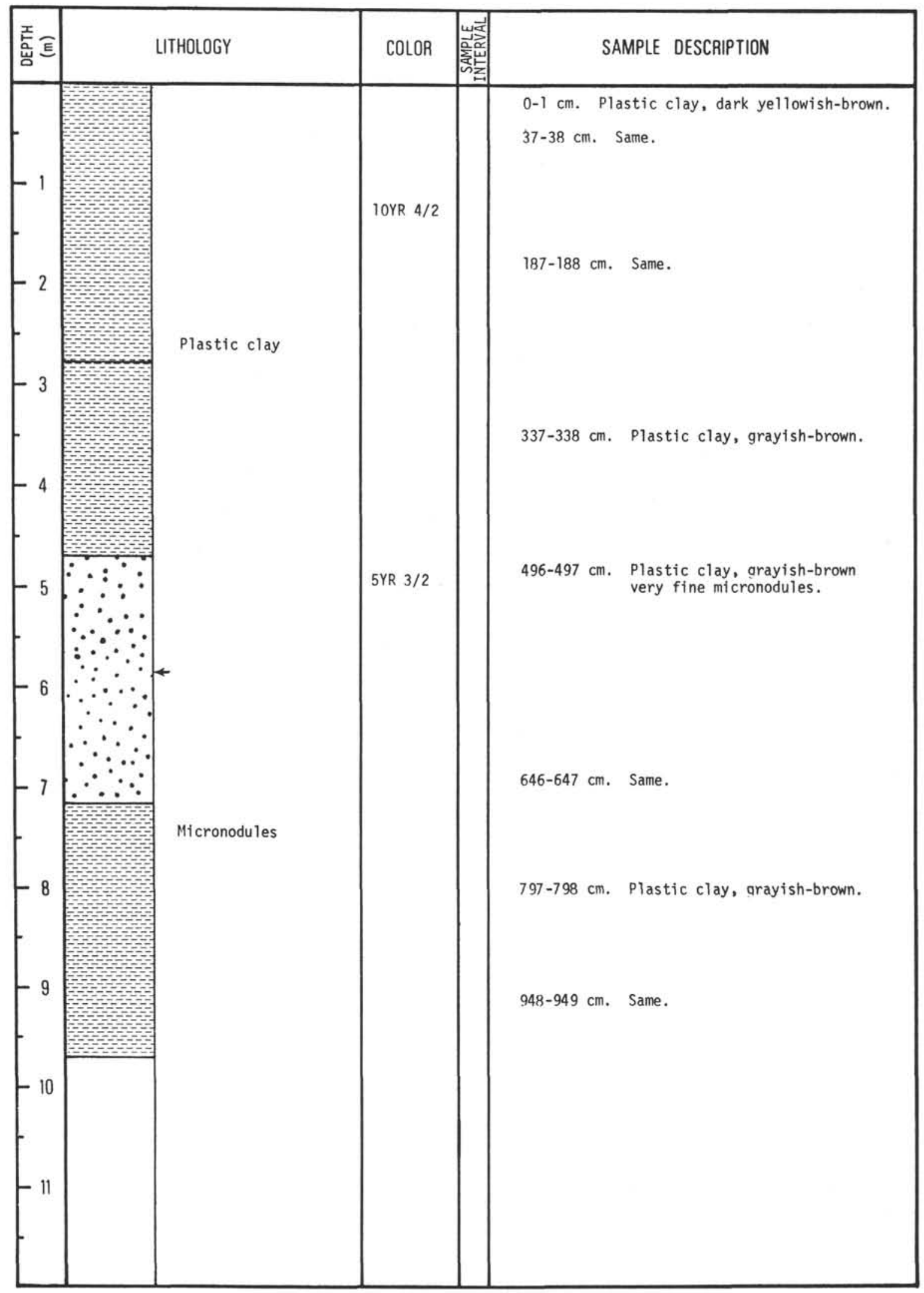

Summary of Piston Core 7. 